\title{
PENGARUH DOPING DAN PERLAKUAN PANAS TERHADAP KEKERASAN KERAMIK PADA BAHAN DASAR PEMBUATAN POCI
}

\author{
Axel Nathanael $^{\text {a) }}$, Agus Setyo Budi ${ }^{\text {b) }}$, Widyaningrum Indrasaric ${ }^{\text {c) }}$ \\ Fisika, FMIPA, Universitas Negeri Jakarta, Jl. Rawamangun Muka No. 1 RT 11 Rw 14, Pulo Gadung, Kota \\ Jakarta Timur 13220, Indonesia. \\ Email: a)axelnathanaelaja@gmail.com, b)agussb@unj.ac.id ,c) ${ }^{\mathrm{c}}$ widyafisikaunj@gmail.com
}

\begin{abstract}
Abstrak
Poci yang termasuk dalam keramik memiliki kekurangan karena mudah pecah. Beragam cara telah dilakukan untuk meningkatkan kekerasan poci. Salah satu hal yang dilakukan adalah dengan menambah doping dan melakukan perlakuan panas. Perlakuan panas yang dapat dilakukan adalah dengan melakukan variasi suhu pemanasan, lamanya waktu pemanasan, hingga variasi laju pemanasan. Tujuan paper ini adalah mengetahui pengaruh penambahan doping dan perlakuan panas terhadap tingkat kekerasan keramik. Metode yang digunakan adalah studi literatur terhadap penelitian terkait. Hasil yang didapat adalah keramik akan semakin keras bila ditambahkan dengan material tertentu namun kekerasan akan berkurang setelah melebihi komposisi optimumnya. Hal yang sama didapatkan pada perlakuan panas, sekamin lama dan semakin tinggi suhu akan menigkatkan kekerasan keramik sampai batas optimumnya. Hasil ini akan digunakan untuk menentukan komposisi dan suhu yang paling optimumdalam memperkuat keramik.
\end{abstract}

Kata-kata kunci: Poci, Keramik, Suhu, Doping, Kekerasan

\begin{abstract}
The pot that is included in ceramics has a disadvantage because it breaks easily. Various ways have been done to increase pot hardness. One of the things done is to add doping and heat treatment. The heat treatment that can be done is to vary the heating temperature, the length of time for heating and the variation of the heating rate. The purpose of this paper is to determine the effect of the addition of doping and heat treatment on the level of hardness of ceramics. The method used is the study of literature on related research. The results obtained are ceramics that will be harder when added to certain materials, but the hardness will decrease after exceeding its optimum composition. The same thing is found in heat treatment, long time and higher temperature will increase the hardness of ceramics to the optimum. This result will be used to determine the optimum composition and temperature for strengthening ceramics.
\end{abstract}

Keywords: Pot, Ceramic, Temperature, Doping, Hardness 


\section{PENDAHULUAN}

Poci tanah liat dipakai dalam berbagai macam budaya karena memiliki keunikan tersendiri. Namun poci sebagai salah satu keramik memiliki kekurangan yaitu mudah pecah. Oleh sebab itu poci perlu ditingkatkan kualitas mekaniknya. Selain poci, keramik juga dapat ditemukan dalam berbagai bentuk. Dalam beberapa tahun terakhir, keramik semakin banyak digunakan dalam berbagai hal dikarenakan sifatnya yang unik jika dibandingkan dengan logam dam polimer. Keunikan keramik terletak pada kekerasan, kekakuan, dan kerapatannya yang rendah. Keramik diketahui lebih memiliki banyak kegunaan dibandingkan material lain, keramik dapat ditemukan mulai dari perlengkapan rumah tangga, komponen elektronik dll. Karena hal ini, dalam beberapa dekade terakhir peneliti mengembangan fungsi keramik didasarkan pada daya tahan, kekerasan sifat superkonduktor, dielektrik dan lain sebagainya [1]. Untuk menigkatkan kekerasan keramik dapat dilakukan dengan berbagai cara, mulai dari perlakuan panas, diberi doping, hingga ditekan [2], [3]. Awalnya pengembangan keramik dilakukan dengan cara menambahkan doping untuk meningkatkan kekuatan mekanik, salah satu contohnya adalah penambahan silika [4]. Setelah berbagai macam doping digunakan sehingga peneliti mulai mencari cara lain untuk meningkatkan kekerasan keramik, salah satunya dengan menekan keramik. Namun penekanan tidak dapat menunjukan hasil yang memuaskan dikarenankan faktor yang paling memengaruhi adalah suhu [5].

Pengembangan lebih lanjut adalah melakukan variasi suhu. Suhu berpengaruh dengan sifat mekanik dari kristal, karena dalam perlakuan panas terjadi berbagai reaksi kimia pada keramik. Mulai dari pengeringan, penguraian bahan organik, penguapan air, peruraian karbonat, sulfat, dan lainnya [6]. Bersamaan dengan terjadinya reaksi kimia, terjadi pula perubahan fisis yang terjadi bila material terus dipanaskan. Mulailah terjadi perubahan struktur mikro secara bertahap, pertama perataan permukaan partikel disusul dengan pembentukan grain boundary (batas bulir) melalui pertumbuhan leher antar partikel, difusi dan penurunan porositas. Kedua, penyusutan pori antar grain boundary sehingga menurunkan jumlah porositas dan perlahan-lahan grain akan tumbuh. Diakhiri dengan mengecilnya pori dan terselip diantara grain boundary [7], [8]. Pada paper ini akan dilakukan studi literatur mengenai cara peningkatan kekerasan keramik sehingga diperoleh metode yang tepat untuk memperkuat keramik khususnya poci.

\section{METODOLOGI}

Pada artikel ini difokuskan untuk mengkaji metode yang paling optimal terhadap peningkatan kekerasan keramik. Penelitian yang digunakan adalah studi literatur terhadap penelitian yang telah dilakukan sebelumnya. Penelitian pertama, Husain dkk melakukan penelitian yang bertujuan untuk melihat pengaruh penambahan doping abu sekam padi dan suhu pemanasan keramik. Penelitian yang dilakukan oleh Lestari dkk bertujuan untuk melihat perbedaan permukaan sampel dan kristalinitas sampel dengan pengaruh variasi suhu pemanasan. Penelitian selanjutnya, yang dilakukan oleh khalil, bertujuan melihat melihat pengaruh laju pemanasan sampel menggunakan high-frequency induction heat sintering (HFIHS) terhadap permukaan dan kekerasan sampel. Penelitian selanjutnya yang dilakukan oleh Srichumpong dkk meneliti pengaruh lamanya waktu pemanasan material untuk keperluan gigi palsu.

\section{HASIL DAN PEMBAHASAN}

Sampel keramik yang diberi doping dan perlakuan panas berbeda akan memiliki nilai kuat tekan yang berbeda pula [9]. Keramik berbahan lempung akan diberi variasi doping abu sekam padi dari 0 hingga 50\% dengan variasi $10 \%$ kemudian masing masing sampel akan dipanaskan dengan suhu $700^{\circ} \mathrm{C}, 800^{\circ} \mathrm{C}$ dan $900^{\circ} \mathrm{C}$. Hasil yang didapat adalah pada suhu $700^{\circ} \mathrm{C}$ nilai kuat tekan terkecil dimiliki oleh sampel keramik tanpa tambahan abu sekam padi dengan nilai kuat tekan sebesar 64.20 $\mathrm{kg} / \mathrm{cm}^{3}$ sedangkan nilai terbesar diperoleh keramik dengan jumlah abu sekam padi sebesar $30 \%$ dengan nilai kuat tekan sebesar $115.58 \mathrm{~kg} / \mathrm{cm}^{3}$. Nilai kuat tekan kemudian berangsur turun dengan bertambahnya komposisi. Pada suhu $800^{\circ} \mathrm{C}$ hasil yang didapat juga tidak jauh berbeda, nilai tekan terendah terjadi pasa sampel tanpa abu sekam padi, $77.05 \mathrm{~kg} / \mathrm{cm}^{3}$, dan tertinggi terjadi pada 
komposisi $10 \%, 20 \%, 30 \%, 115.58 \mathrm{~kg} / \mathrm{cm}^{3}$, kemudian turun lagi. Sedangkan pada suhu $900^{\circ} \mathrm{C}$ hasil yang berbeda di dapatkan. Keramik memiliki nilai kuat tekan yang sama pada komposisi $10-50 \%$ dengan nilai sebesar $128.42 \mathrm{~kg} / \mathrm{cm}^{3}$ dan sebesar $89.89 \mathrm{~kg} / \mathrm{cm}^{3}$ pada keramik tanpa doping [10]. Hasil pengukuran dapat dilihat pada TABEL 1 .

Pada percobaan lain, sampel keramik dengan perbandingan 95 :5 untuk keramik dan abu sekam padi. Sampel tersebut kebudian dipanaskan menggunakan tanur dengan variasi suhu $900 \mathrm{oC}, 1000 \mathrm{oC}$ dan $1100 \mathrm{oC}$ lalu sampel kemudian dikarakterisasi menggunakan Scanning electron Microscopy (SEM) untuk melihat mikrostruktur dari sampel [11] dan karakterisasi menggunakan X Ray Diffraction (XRD) untuk melihat kristalinitas sampel [12]. Hasil SEM menunjukan bahwa mikrostruktur sampel pada setiap variasi suhu akan semakin padat dan menyatu, namun permukaan sampel akan semakin tidak rata dan memiliki pori yang besar yang menyebabkan menurunnya densitas. Hasil XRD sampel yang dipaaskan pada suhu $900 \mathrm{oC}$ menunjukan satu puncak luas kecil sebelum munculnya puncak serapan tajam pertama yang menandakan sampel masih bersifat amorf [13].

TABEL 1. Nilai Kuat Tekan Keramik [10]

\begin{tabular}{|c|c|c|c|}
\hline \multirow{2}{*}{$\begin{array}{c}\text { Lempung : Abu } \\
\text { sekam padi }\end{array}$} & \multicolumn{3}{|c|}{ Kuat tekan $(\mathrm{kg} / \mathrm{cm} 3)$} \\
\cline { 2 - 4 } & $700^{\circ} \mathrm{C}$ & $800^{\circ} \mathrm{C}$ & $900^{\circ} \mathrm{C}$ \\
\hline $100: 0$ & 64.2 & 77.05 & 89.89 \\
$90: 10$ & 77.05 & 115.58 & 128.42 \\
$80: 20$ & 77.05 & 115.58 & 128.42 \\
$70: 30$ & 115.58 & 115.58 & 128.42 \\
$60: 40$ & 102.94 & 102.74 & 128.42 \\
$50: 50$ & 89.89 & 102.74 & 128.42 \\
\hline
\end{tabular}

Memanaskan material dapat dilakukan dengan berbagai cara, mulai menggunakan tanur/furnace, microwaves, spark plasma sintering, high-frequency induction heat sintering (HFIHS) [14], [15]. HFIHS merupakan metode sintering yang memanfaatkan panas dari listrik berfrekuensi tinggi yang dialirkan ke gulungan logam. Sehingga memanaskan balok grafit di tengah gulungan dan disaat bersamaan material akan ditekan dari kedua arah. Konfigurasi HFIHS secara umum ditunjukan pada GAMBAR 1.

Sampel masing masing akan dipanaskan pada suhu $1300^{\circ}, 1400^{\circ}, 1450^{\circ}$ dan $1500^{\circ}$ dengan laju pertambahan panas sebesar $200 \mathrm{oC} / \mathrm{min}$ dan $700 \mathrm{oC} / \mathrm{min}$. Sampel yang dipanaskan dengan laju 200oC/min memiliki sampel dengan ukuran bulir yang kecil yang menggumpal dan memiliki banyak pori dikarenakan suhu $1300 \mathrm{oC}$ terlalu rendah untuk sintering. Sedangkan sintering pada suhu 1400 $1450 \mathrm{oC}$, menunjukan bulir yang homogen dan tidak menggumpal, hal ini membuat mikrostruktur sampel lebih padat dan menambah pori. Pada suhu 1500oC, ukuran bulir meningkat dikarenakan suhu sintering yang tinggi. Bulir yang tidak normal muncul ketika sampel dipanaskan dalam waktu yang lama (laju pemanasan yang lama, $200 \mathrm{oC} / \mathrm{min})$ dan suhu tinggi $(1500 \mathrm{oC})$. Pada pemanasan $700 \mathrm{oC} / \mathrm{min}$, sampel memiliki ukuran bulir relatif kecil, kurang dari $200 \mathrm{~nm}$, namun lebih banyak pori yang dihasilkan. Dapat disimpulkan laju pemanasan minimal $200 \mathrm{oC} / \mathrm{min}$ akan menghasilkan struktur yang homogen dan ukuran bulir rata rata $500 \mathrm{~nm}$. Rata rata kerapatan dan nilai kekerasan dari sampel akan meningkat seiring dengan meningkatnya suhu sintering. Kelenturan atau ductilitiy sampel bergantung dengan meningkatnya ukuran bulir sampel saat berlangsungnya proses sintering. Sampel yang dipanaskan dalam laju 200oC/min akan memiliki kelenturan yang besar namun memiliki kekuatan yang rendah sekitar $185 \mathrm{MPa}$. Kekerasan sampel akan sedikit meningkat saat laju pemanasan $400 \mathrm{oC} / \mathrm{min}$, nilai kekerasan sampel akan mencapai 192.7 Mpa maksimal, setelah itu nilai kekerasan akan berkurang seiring dengan pertambahan laju pemanasan [16]. 


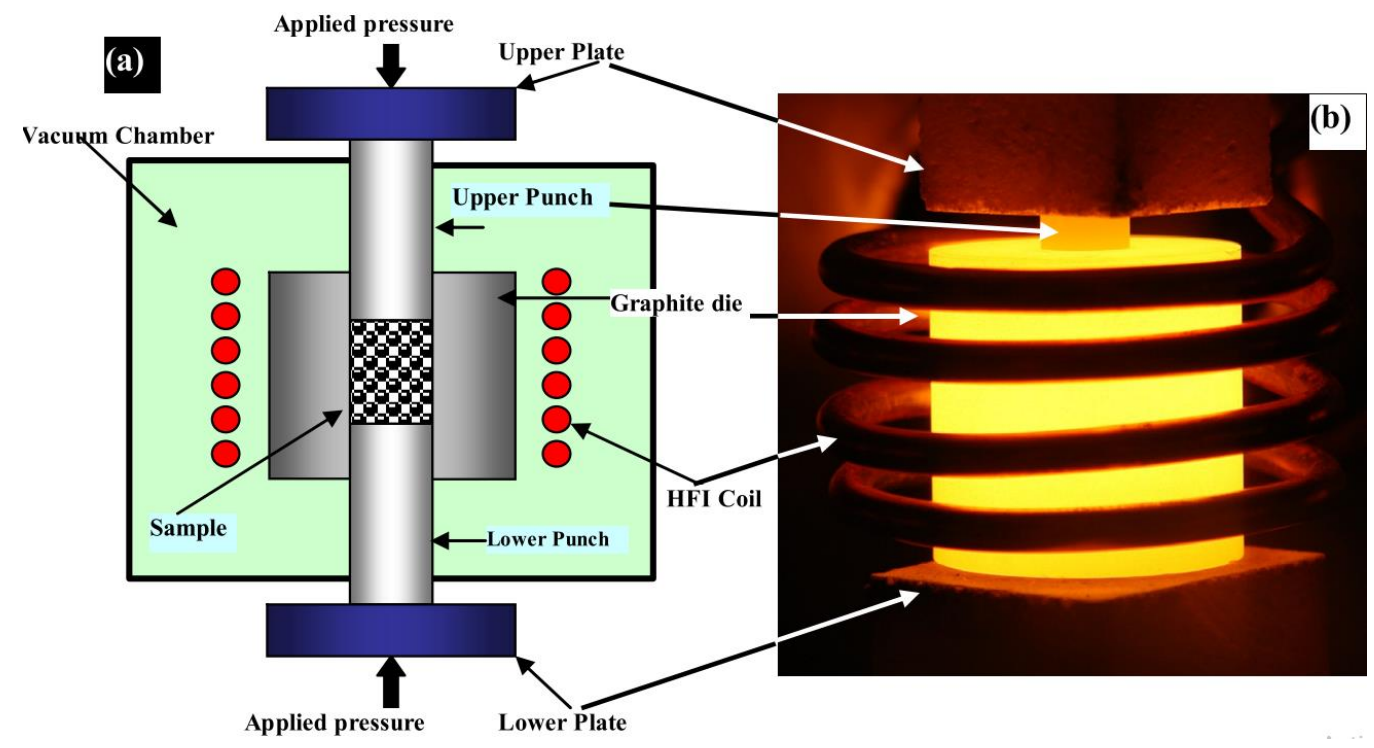

GAMBAR 1. Konfigurasi HFIHS (a) Skema susunan HFIHS, (b) Foto balok grafit yang memanas [16]

Keramik juga dapat digunakan dalam bidang kesehatan, salah satunya dalam gigi. Gigi buatan yang digunakan untuk menggantikan gigi asli yang sudah hilang [17]. Material yang dibutuhkan untuk membuat gigi palsu biasanya merupakan campuran keramik kaca bercampur mika. Material itu dipakai karena bersifat kuat, memiliki resistivitas tinggi terhadap panas [18], [19]. Sampel ynag terdiri dari $\mathrm{SiO}_{2}, \mathrm{Al}_{2} \mathrm{O}_{3}, \mathrm{MgO}, \mathrm{MgF}_{2}, \mathrm{SrCO}_{3}, \mathrm{CaCO}_{3}, \mathrm{CaF}_{2}$ dan $\mathrm{P}_{2} \mathrm{O}_{5}$ akan dicampur dan dibakar dalam tanur pada suhu $1420^{\circ} \mathrm{C}$ dan di quenching dengan air dingin. Kemudian akan dilelehkan pada suhu yang sama, kemudian dipanaskan pada suh $\mathrm{u} 580^{\circ} \mathrm{C}$ selama 1 jam 30 menit untuk mengurangi stres [20]. Sampel kemudian dipanaskan pada suhu $643^{\circ} \mathrm{C}$ dan diberi variasi waktu 3, 6, 12, 24, 48 dan 72 jam untuk melihat perubahan struktur dan kekerasannya. Struktur yang didapatkan saat sampel di panaskan selama 3 akan menghasilkan permukaan yang rata dan memiliki ukuran besar. Semakin lama waktu pemanasan membuat kristal yang terbentuk semakin mengecil sehingga menghasilkan pori yang lebih banyak. Sampel selanjutnya akan kekuatan strukturnya, sampel yang dipanaskan selama 3 jam memiliiki kekrasan sebesar 295.7 HV dan akan terus bertambah seiring bertambahnya waktu sampai kekerasan tertinggi didapatkan saat dipanaskan selama 72 jam yaitu 393 HV. Data kekerasan sampele dapat dilihat pada TABEL 2. Semakin lama sampel dipanaskan ukuran kristal sampel akan semakin mengecil hal ini membuat struktur sampel semakin kokoh [21].

TABEL 2 Kekerasan sampel dengan variasi waktu pemanasan [21]

\begin{tabular}{c|cccccc}
\hline Hardness $(\mathrm{HV})$ & 3 jam & 6 jam & 12 jam & 24 jam & 48 jam & 72 jam \\
\hline Rata rata & 285.7 & 302.6 & 333.4 & 35103 & 377 & 393 \\
\hline
\end{tabular}

\section{SIMPULAN}

Kekerasan keramik dapat diperoleh dengan beberapa cara, mulai dari menambah doping, memanaskan pada suhu tinggi, mengubah laju pemanasan hingga waktu dalam memanaskan. Sampel akan semakin keras bila ditambahkan dengan material tertentu namun kekerasan akan berkurang setelah melebihi komposisi optimumnya. Hal tersebut juga terjadi dengan laju pemanasan, semakin tinggi laju pemanasnasn maka material akan semakin keras sampai akhirnya menurun setelah melewati laju optimumnya. Sedangkan suhu pemanasan akan membuat struktur material semakin mengecil hal ini membuat sampel semakin keras, hal ini juga berlaku untuk waktu pemanasan material.Gambar dan tabel. 


\section{REFERENSI}

[1] K. Abdelrazek, S. W. Kim and H. Y. Kim, "Effect Of High-Frequency Induction Heat Sintering Conditions On The Microstructure And Mechanical Properties Of Nanostructured Magnesium/Hydroxyapatite Nanocomposites," Mater, Des, 2012.

[2] R. S. Mishra et al., "High-pressure sintering of nanocrystalline $\gamma$-Al2O3," Ceram, vol. 79, pp. 2989-2992, 1996, doi: https://doi.org/10.1111/j.1151- 2916.1996.tb08741.x.

[3] F. M. Liu et al., "Bimodal transparent alumina ceramics prepared with micro/nano-particles under high pressure," Scr. Mater, vol. 122, pp. 54-58, 2016, doi: https://doi.org/10.1016/j.scriptamat.2016.05.017.

[4] A. M. Daifullah, B. Girgis and H. M. Gad, "Utilization of Agro Residues (Rice Husk) in Small Waste Water treatment Plants," Mater. Lett, vol. 57, pp. 1723-1731, 2003.

[5] M. N. Rahaman, "Sintering of Ceramics," CRC Press Taylor Fr. Gr, 2008.

[6] Ramlan and A. A. Bama, "Pengaruh Suhu dan Waktu Sintering terhadap Sifat Bahan Porselen untuk Bahan Elektrolit Padat (Komponen Elektronik)," Penelit. Sains, vol. 14, pp. 22-25, 2011.

[7] Ramlan, "Pengaruh $\mathrm{MgO}$ dan Suhu Sintering Terhadap Mikrostruktur dan Sifat Fisis Keramik Beta," Universitas Indonesia, 2001.

[8] J. S. Reed, "Introduction to the Principles of Ceramic Processing," John Wiley \& Son, pp. 583-598, 1995.

[9] N. V. Mohan, P. P. V. Satyanarayana, and K. S. Rao, "Performance Of Rice Husk Ash Bricks,” Int. J. Eng. Res. Appl, vol. 2, pp. 1906-1910, 2012.

[10] S. Husain, N. H. Haryanti, and T. N. Manik, "Pengaruh Suhu Sintering Terhadap Sifat Mekanik Keramik Berbahan Lempung dan Abu Sekam Padi," Fis. FLux, vol. 13, pp. 1-10, 2016.

[11] C. V. Lazaratou, D. V. Vayenas and D. Papoulis, "The role of clays, clay minerals and claybased materials for nitrate removal from water systems: A review," Appl. Clay Sci, p. 105377, 2019, doi: 10.1016/j.clay.2019.105377.

[12] H. U. Jamo and S. G. Abdu, "Structural Analysis And Aurface Morphology Of Quartz," Bayero J. Pure Appl. Sci, vol. 9, no. 2, pp. 33-37, 2014, doi: 10.4314/bajopas.v9i2.40.

[13] L. Lestari et al., "Evolusi Mikrostruktur Dari Keramik Paduan Silika (SiO2) dan Alumina (Al2O3)," Apl. Fis, vol. 13, pp. 1-6, 2017.

[14] K. A. Khalil and S. W. Kim, "Effect of Processing Parameters on the Mechanical and Microstructural Behavior of Ultra-Fine Al2O3- ( $\mathrm{ZrO} 2+8 \% \mathrm{Mol}$ Y2O3) Bioceramic, Densified By High Frequency Induction Heat Sintering,” Int. J. Appl. Ceram. Technol, vol. 3, pp. 322-330, 2006.

[15] D. Jiang et al., "Spark plasma sintering: a high strain rate low temperature forming tool for ceramics," Mater. Sci. Eng. A, vol. 463, pp. 89-93, 2007.

[16] K. A. Khalil, “Advanced Sintering of Nano-Ceramic Materials," 2014, doi: 10.5772/38287.

[17] J. Zhao and X. Wang, “Advanced Ceramics for Dentistry,” Elsevier Inc, pp. 23-48, 2014.

[18] J. Y. Thompson, S. C. Bayne and H. O. Heymann, "Mechanical properties of a new micabased machinable glass ceramics for CAD/CAM restorations," J. Prosthet Dent, vol. 76, pp. 19-23, 1996.

[19] E. E. Meliegy and R. V. Noort, "Machinable Mica Dental Glass-Ceramics, in: Glasses and Glass Ceramics for Medical Applications,” Springer Inc., New York, pp. 192-208, 2012. 
[20] Kuntajinda, "Residual Strain Adjustment to Enhance Machinable Glass-Ceramics Forming As A Restorative Dental Material Using CAD/CAM System," Kasetsart University, 2011.

[21] T. Srichumpong et al., "Effect of Heat Treatment Time on Properties of Mica-Based GlassCeramics for Restorative Dental Materials Effect of Heat Treatment Time on Properties of Mica-Based Glass- Ceramics for Restorative Dental Materials," Eng. Mater, 2016, doi: 10.4028/www.scientific.net/KEM.702.23. 